\title{
PREPARANDO UN PUEBLO PARA EL TIEMPO DE ANGUSTIA
}

MTRO. CRISTIAN S. GONZALES

Centro de Investigación Adventista

Universidad Peruana Unión

Perú 


\title{
Resumen
}

Preparando un pueblo para el tiempo de angustia. Este artículo describe de manera resumida cómo Dios desea que su pueblo se prepare para el tiempo de angustia, luego de que el tiempo de gracia se cierre. En este tiempo de angustia, el Espiritu Santo es quién guiará a la iglesia y no los pastores. Pero para recibir esta guía espiritual, Dios espera que sus hijos se preparen. De esta manera, se aborda este tema a partir de los escritos de Ellen G. White y serán presentados de manera sistematica a partir de un estudio documental de fuentes primarias. El contenido de sus escritos no será presentado en una sucesión histórica de eventos futuros, porque muchos de estos eventos finales sucederán de manera paralela.

Palabras clave: Tiempo de angustia, crisis final, tiempo del fin, preparación final.

\begin{abstract}
Preparing a People for the Time of Trouble. This article describes in a sumarized way how God wants His people to be prepared for the time of trouble, after the closing of the probation time. In this time of trouble, The Holy Spirit is the one who will lead the Church and not the elders. However, in order to receive this spiritual guidance, God expects His children to be prepared. Therefore, this topic is taken based on Ellen G. White writings and systematically organized from a documentary study of the primary sources. The content of her writings is not given in a historical succession of the future events because many of these final events will take place simultaneously.
\end{abstract}

Keywords: Time of trouble, final crisis, time of the end, final preparation.

Recibido: 02/03/2021

Aceptado: 20/10/2021 
Estrategias para el Cumplimiento de la Misión 19, no. 1 (2021): 45-69

\title{
PREPARANDO UN PUEBLO PARA EL TIEMPO DE ANGUSTIA
}

\author{
Mtro. CRISTIAN S. GONZALES \\ Centro de Investigación Adventista \\ Universidad Peruana Unión \\ Perú
}

\section{Introducción}

La humanidad, a través de la historia, ha enfrentado en diferentes momentos diversos tipos de crisis. Sin embargo, Jesús advirtió que cerca de su segunda venida habrá una crisis que será sin precedentes y será conocida como la "gran tribulación" (Mt 24:21). Esta gran tribulación exigirá, de parte de los ministros del evangelio, una gran preparación puesto que la iglesia exigirá de ellos una atención mayor por causa de los terribles momentos que soportará en ese tiempo. Asimismo, el mensaje de los tres ángeles de Apocalipsis 14:6-12, recuerda que la iglesia tiene una gran misión y un gran mensaje que tiene que ser anunciado. Asimismo, el pueblo de Dios recibirá la ayuda del poder del Espiritu Santo, ellos al ser llenos de este poder darán a conocer este mensaje que será la última amonestación al mundo.

En este contexto se cumplirán las palabras de Jesús acerca de la predicación al mundo entero por testimonio y luego vendría el fin $(\mathrm{Mt}$ 24:14). Entonces, al cumplir con el mandato de la predicación, se promulgará el decreto de la ley dominical con pena de muerte y con esto el tiempo de gracia llegará a su fin para dar lugar al tiempo de angustia. En ese tiempo, el pueblo de Dios experimentará una angustia profunda, conocida como la angustia de Jacob, y al final, se presenciará de manera visible la segunda venida de Cristo. Por tanto, el proposito de este artículo es ofrecer un breve panorama sobre cómo debe ser la preparación de la iglesia para el tiempo de angustia a partir de los escritos de Ellen G. White. Estos fueron analizados en su idioma original y contexto inmediato. A partir de un estudio documental de estos escritos serán expuestos de manera sistematica, pero no cronológica. Para una mejor comprensión de este tema, lo primero que se hará es presentar el fundamento bíblico 
seguido de los comentarios de Ellen G. White agrupados temáticamente de la siguiente manera: fuerte promesa: tomando la armadura de Dios, fuerte clamor: salid de ella pueblo mío, y la iglesia en el tiempo de angustia y su liberación final.

\section{Fundamento bíblico}

Liderar en el tiempo de angustia exige una gran preparación que solo Dios puede realizar. Esta preparación exige una purificación previa para poder enfrentar la gran apostasía. La condición laodicense descrita en Apocalipsis 3:14-21 muestra que el pueblo de Dios tiene que luchar de manera decidida para abandonar su condición. Asimismo, el mensaje de los tres ángeles de Apocalipsis 14:6-12 se presenta para lograr este objetivo divino. Hans K. LaRondelle menciona que este mensaje

expresa el llamamiento final del cielo a toda la gente para que renuncie a cada forma de idolatría y falsedad, y adore al Creador y acepte su evangelio eterno. En vista de la amenaza final del anticristo, Dios requiere una fidelidad doble: fidelidad al testimonio de Jesús y obediencia a los mandamientos de Dios (Apoc. 14:12). ${ }^{1}$

De esta manera, el mensaje del primer ángel (Ap 14:6-7) enfatiza varios aspectos esenciales para el tiempo del fin: (1) su alcance universal (cf. Mt 28:18-20), (2) Dios es presentado como el único que merece adoración y gloria (cf. Éx 20:3), (3) el mensaje aparece en el contexto del juicio (Dn 7:914; 8:14; por lo tanto, apunta a 1844) y (4) recuerda al Creador y su ley (cf. Éx 20:3-17). Así, "el propósito del mensaje del primer ángel" restaura "la adoración verdadera" y prepara "a los habitantes de la Tierra para la segunda venida de Cristo". ${ }^{2}$ El mensaje del segundo ángel (Ap 14:8) apunta hacia la caída de Babilonia (cf. Ap 17:1-6; 18:2, 4, 8) que es descrita como la "mujer sentada sobre una bestia escarlata llena de nombres de blasfemia" (Ap 17:3) la cual representa a la una iglesia infiel, que es guiada por el enemigo de Dios. Por lo cual, "tanto la babilonia apocalíptica como la

1 Hans K. LaRondelle, "Remanente y mensajes de los tres ángeles", en Tratado de Teología Adventista del Séptimo Día, ed. Raoul Dederen, trad. David P. Gullón (Florida: Asociación Casa Editora Sudamericana, 2009), 980.

$2 \quad$ Ibíd., 984.

3 En caso se indique lo contrario, las citas bíblicas han sido tomadas de la versión ReinaValera 1995.

https://doi.org/10.17162/recm.v19i1.1546 
cristiandad apóstata culminan en una alianza de poderes eclesiásticos y político-civiles 'para consolidar el dominio religioso sobre la política.'"4

El mensaje del tercer ángel (Ap 14:9-12) menciona la sanción sobre aquellos que adoran a la bestia y su imagen, ellos recibirán su marca. El tipo de sanción es beber de la copa de la ira de Dios (v. 10; cf. 16:1-17). Asimismo, este mensaje advierte que aquellos que reciben la marca de la bestia recibirán "la ira de Dios sin mezcla de misericordia, la cual será derramada en las siete últimas plagas". ${ }^{5}$ En contraste, la señal divina de aprobación " $\mathrm{y}$ protección se llama 'el sello del Dios vivo', la cual sus ángeles colocan en las frentes de todos los que rechazan la marca de la bestia". ${ }^{6}$ Por tanto, los tres mensajes angélicos constituyen el mensaje del evangelio eterno (Mt 24:14; Jn 5:46, 47; Col 1:23; Gá 1:7, 8; 1 Co 15:3-11; Ef 2:20, etc.). Es importante recalcar que este triple mensaje angelical es mejor entendido a partir de Apocalipsis 10. Este texto menciona que se abre el librito (vv. 2, 8) que es una clara alusión al libro de Daniel que fue sellado en su tiempo (Dn 12:4). Así, Apocalipsis 10:8 y 22:10 señalan que el sello sobre el libro de Daniel ha sido abierto y no hay necesidad de sellar Apocalipsis pues el tiempo está cerca. ${ }^{7}$

Finalmente, este triple mensaje de misericordia al mundo tiene como propósito restaurar la verdadera adoración a Dios como Creador y único merecedor de toda alabanza. Esto es posible solo a través de la obediencia a su Palabra, siendo el sábado la señal visible de dicha verdadera adoración e identidad de su pueblo.

\section{Fuerte promesa: "vístete de la armadura de Dios"}

A través de sus escritos, Ellen G. White advierte que en el tiempo de angustia la fe del pueblo de Dios será probada de una manera inimaginable a los ojos humanos. El tiempo de angustia será horrible. ${ }^{8}$ Por eso, ella "oró para que pudiéramos ser bautizados en los sufrimientos de Cristo, para que no nos encogiéramos en las pruebas, pero soportarlos con paciencia y

$4 \quad$ LaRondelle, "Remanente y mensajes de los tres ángeles", 985.

$5 \quad$ Ibíd., 987

$6 \quad$ Ibíd.

$7 \quad$ Ibíd., 981-982.

8 Ellen G. White, Manuscript 6, 1849, Centro de Investigación White, Universidad Peruana Unión, Lima, Perú (CIW-UPeU). Todas las citas textuales tomados del CIWUPeU o de algún otro documento en inglés, han sido traducidas por el autor. 
alegría, sabiendo lo que Jesús había sufrido." ${ }^{\prime 9}$ Asimismo, ella exhorta a tomar la armadura de Dios. Esta armadura espiritual fue presentada por el apóstol Pablo, en Efesios 6:10-20. Ella dice,

sigamos con toda la armadura de Dios para que podamos estar listos para la batalla en cualquier momento. Tendremos que luchar cada centímetro de tierra ahora. Satanás ha descendido con gran poder, sabiendo que su tiempo es corto; pero con los mandamientos de Dios escritos en nuestros corazones y en nuestras mentes [nosotros] seguiremos fuertes y audaces, y aunque los hijos de Anak sean muchos y altos, seguiremos llorando, los mandamientos de Dios y el testimonio de Jesús. ${ }^{10}$

Para enfrentar esta batalla espiritual es necesario que el pueblo de Dios mantenga la unidad (Jn 17:20-21). Ella explica que los que aceptan el sábado, "están unidos en sus puntos de vista y comprensión de las verdades bíblicas en todos los puntos importantes". ${ }^{11}$ Por el contrario, los que se oponen al sábado, "están divididos", son "líderes ciegos" que "podrían cometer fácilmente un error para que parezca verdad".$^{12}$ Ellen G. White añade que, "si no pueden ponerse de acuerdo juntos aquí, no pueden reinar juntos en el cielo". ${ }^{13}$ Asimismo, agrega,

Dios está conduciendo a un pueblo y no a unas cuantas personas separadas aquí y allá, una que cree una cosa y otra que cree otra diferente. Los ángeles de Dios están efectuando la obra confiada a su cuidado. El tercer ángel va a la cabeza y está purificando a un pueblo, y éste debiera avanzar con él en forma unida. Algunos toman la delantera a los ángeles que están guiando a su pueblo; pero tienen que desandar cada paso y seguir humildemente al mismo paso que los ángeles que guían. ${ }^{14}$

De esta manera, se nos indica que la manera de que la unidad sea posible, es imperante que la iglesia se mueva bajo el liderazgo divino.

9 Ellen G. White, A Sketch of the Christian Experience and Views of Ellen G. White (Saratoga Springs, NY: James White, 1851), 55.

10 Ellen G. White a Hastings, Brother and Sister, 12 de abril de 1849, carta 5, 1849, CIWUPeU.

11 Ellen G. White, Manuscript 5, 1851, CIW-UPeU.

12 Ibíd.

13 White, MS 6, 1849, CIW-UPeU.

14 Ellen G. White, Testimonios para la iglesia (Doral, FL: Asociación Publicadora Interamericana, 2003), 1:190.

https://doi.org/10.17162/recm.v19i1.1546 


\subsection{La Palabra de Dios y su sello}

Ellen G. White advierte que la Biblia es "el libro de estatutos que debía juzgarnos en los últimos días". ${ }^{15}$ Sin embargo, su estudio ha sido descuidado y menospreciado. ${ }^{16}$ Ella pregunta a los que fueron negligentes en su preparación durante años "¿cómo van a resistir?... las verdades que hemos estado aprendiendo durante años deben ser aprendidas en unos pocos meses por aquellos que ahora aceptan el Mensaje del Tercer Ángel". ${ }^{17}$ Asimismo, señala que la verdad debe purgar y purificar "las pasiones del corazón natural", debe haber "una ruptura de corazón ante el Señor" y no de "la vestimenta". ${ }^{18}$ Pero, "si alguno perdiera su amor por la Palabra de Dios", debe orar "fervientemente para que Dios los bautice con Su Espíritu para comprender Su Palabra y para que puedan amarla más que cualquier otra cosa". ${ }^{19}$

Además, ella explicó que Dios está preparando "una cobertura" - que es su sello de divino ${ }^{20}$ - para sus hijos fieles que servirá como protección en el tiempo de angustia. Así, los que aceptan la verdad serian cubiertos "con esta cobertura del Dios Todopoderoso", ${ }^{21}$ para que sean cuidados y ocultados. ${ }^{22}$ Esta cobertura es la obediencia a la ley de Dios y a su Palabra, y el sábado será "el muro de separación entre el verdadero Israel de Dios y los incrédulos" ${ }^{23}$ Esta cobertura servirá como un "refugio en el día del Señor", en el día "de la ira ardiente de Dios, en las siete últimas plagas". ${ }^{24}$ Por eso, Jesús en su misericordia "gritó: 'Mi sangre, padre, mi sangre, mi sangre, mi sangre' ... ‘ Esperad! ¡Esperad! ¡Esperad! ¡Esperad! hasta que los siervos de Dios estén sellados en sus frentes'" ${ }^{\prime 25}$

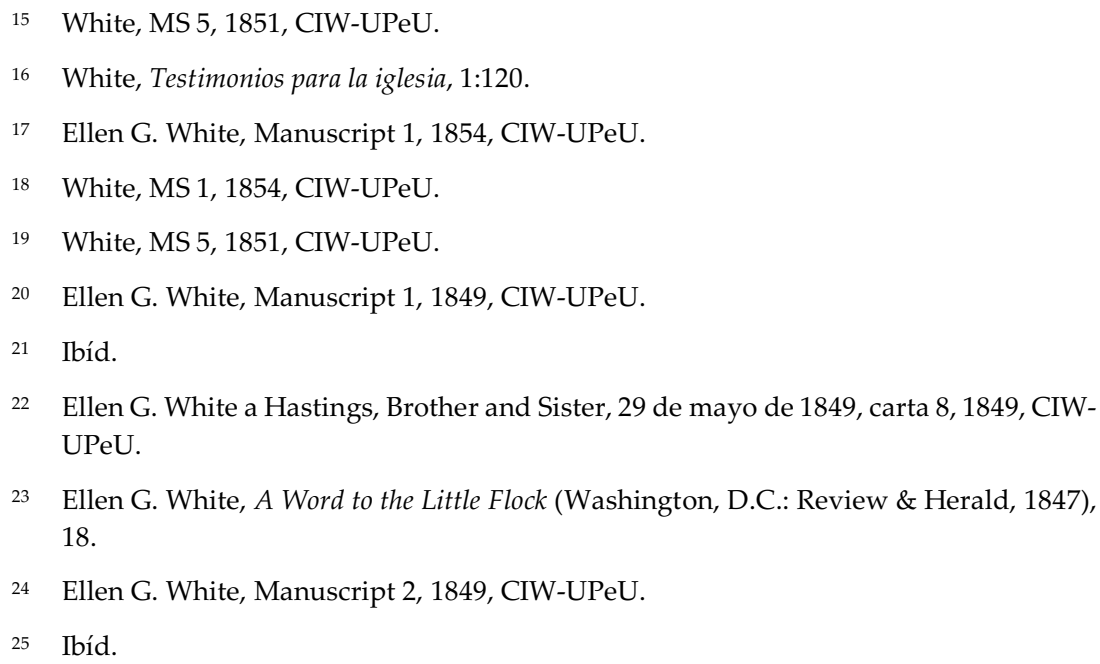


Por tanto, los "pequeños ídolos deben dejarse caer en el camino. No habrá desunión por mucho más tiempo", ${ }^{26} \mathrm{y}$ "no mires para complacerte. Vive para Dios". ${ }^{27}$ Por eso, ella advierte que "no se puede jugar con Dios. Mira, ten cuidado de cómo lo tratas". ${ }^{28}$ Por otro lado, Satanás usará a los "ministros que habían rechazado la verdad de Dios" y el espiritismo para hacer creer que usan el poder de $\operatorname{Dios}^{29} \mathrm{y}$ así evitar la cubierta de Dios sobre sus hijos. ${ }^{30}$

\subsection{Anuncio del evangelio y la benevolencia sistemática}

El apóstol Santiago dice que "la religión pura y sin mancha delante de Dios" consiste en "visitar a los huérfanos y a las viudas en sus tribulaciones y guardarse sin mancha del mundo" (Stg 1:27). Explicando esta cita, Ellen G. White comenta que "no era solo simpatizar con ellos en su aflicción con palabras de consuelo, sino ayudarlos" ${ }^{31}$ De esta manera, "hombres y mujeres jóvenes, pueden obtener una gran bendición ayudando a las viudas y huérfanos en su aflicción". 32 Por lo tanto, "Los pequeños actos de bondad en favor de su hermano en forma secreta unirían sus corazones y serían anotados en el cielo". ${ }^{33}$

Asimismo, Dios requiere que sus hijos lleven una vida sacrificada, porque "Él los ha bendecido" con abundancia y se requiere grandes sacrificios "para poner la verdad ante aquellos que están en la oscuridad" ${ }^{34}$ Ante esta realidad, es importante recordar que, "El cielo será lo suficientemente barato si lo obtenemos a través del sufrimiento" ${ }^{35}$ Pero si la fe está muerta, no se salvarán. ${ }^{36}$ Ella amonesta que hay un trabajo de




salvación que se tiene que realizar de manera urgente y rápida, ella explica que,

Le rogué a Dios que dejara que sus mensajeros fueran y trabajaran rápido para la salvación de las almas. Vi que Dios estaba dispuesto a darnos grandes bendiciones, si solo tuviéramos fe, y cuando salimos entre la gente debemos ir en el nombre del Señor, porque sin Él no podemos hacer nada." ${ }^{\prime 37}$

Este trabajo exige fidelidad y sensibilidad de parte de los hijos de Dios, porque llegará el tiempo cuando el pueblo de Dios dispondrá "de sus propiedades" cuando aparezca un "momento de necesidad". ${ }^{38}$ En este contexto, Dios les mostrará "cuándo vender y cuánto vender", no todos lo harán al mismo tiempo, sino que será de acuerdo a la "necesidad de la obra".$^{39}$ Del mismo modo, ella advierte: "Vi que muchos de los que poseen riquezas no comprarán el oro, ni las vestiduras blancas ni el colirio". ${ }^{40}$ En torno a esta declaración, ella también declara que,

si algunos se aferraban a sus propiedades y no preguntaban al Señor en qué consistía su deber, él no se lo hará conocer y les permitirá conservar sus propiedades, pero en el tiempo de angustia éstas se levantarán delante de ellos como una montaña para aplastarlos, y ellos tratarán de deshacerse de ellas, pero no podrán. Oí a algunos lamentarse así: “La causa languidecía, los hijos de Dios morían por carecer de la verdad, y nosotros no hicimos esfuerzos para suplir la falta; ahora nuestras propiedades no tienen valor. ¡Ojalá que nos hubiésemos librado de ellas y hecho tesoros en los cielos!". ${ }^{41}$

Ella también advirtió que el "objetivo de la venta no era dar a aquellos que pueden trabajar y mantenerse a sí mismos, sino difundir la verdad. Es un pecado apoyar y disfrutar de la ociosidad". ${ }^{42}$ También advierte que se reflexione en el pecado de Ananías y Safira (Hch 5:1-11). Asimismo, ella dice que: "Ahora es el momento de acumular tesoros en el cielo y de poner nuestros corazones en orden, listos para el tiempo de angustia. Aquellos que solo tienen las manos limpias y un corazón puro soportarán ese

37 White, MS 5, 1851, CIW-UPeU.

38

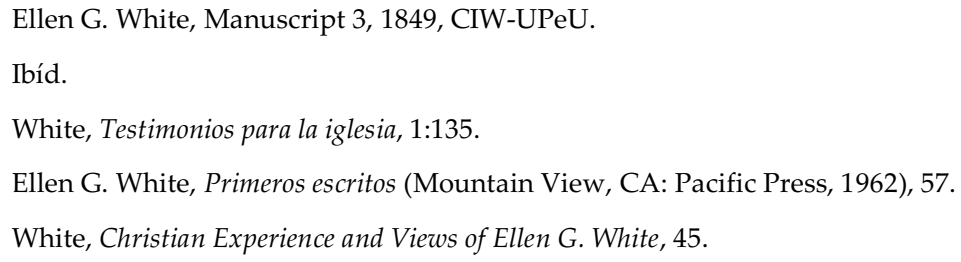

https://doi.org/10.17162/recm.v19i1.1546 
momento difícil". 43 También ella explica que "con el avance de la obra vendría un descubrimiento de maneras y medios", y esto debe considerarse puesto que "lo que no es evidente en la actualidad se revelaría a medida que el trabajo real progresara". ${ }^{4}$

Cuando se imponga la ley dominical sin pena de muerte el pueblo de Dios deberá trabajar así:

Consagrar el domingo al trabajo misionero es arrancar el látigo de las manos de los fanáticos arbitrarios, cuyo placer sería humillar a los adventistas del séptimo día. Cuando vean que dedicamos los domingos a visitar a la gente y explicarles las Escrituras, comprenderán que es inútil querer detener nuestra obra por medio de leyes dominicales. El domingo puede dedicarse a diversas actividades que lograrán mucho resultado para Dios. Pueden celebrarse reuniones al aire libre y en las casas particulares. Puede trabajarse de casa en casa. Los que escriben pueden, en aquel día, redactar artículos para los periódicos. Cuando sea posible, celébrense reuniones religiosas, y hágaselas intensamente interesantes. Hablad con fuerza y seguridad del amor del Salvador, y cantad verdaderos himnos de despertamiento religioso. Hablad de la temperancia y de la vida religiosa genuina. Aprenderéis así el arte de trabajar y alcanzaréis a muchas almas... Dios nos ha dado instrucciones muy claras en cuanto a nuestra obra. Debemos proclamar la verdad con respecto al sábado de Jehová, y reparar la brecha que fue abierta en la ley. Debemos hacer cuanto podamos para ilustrar a los ignorantes; pero jamás debemos asociarnos a hombres del mundo para recibir ayuda financiera..$^{45}$

\subsection{La oración y la fe}

Al hablar de la oración, Ellen G. White afirma que la "oración secreta", es "el alma de la religión". ${ }^{46}$ En ese contexto, sugiere también que se abogue "tan ferviente y ardorosamente como lo haríais por vuestra vida mortal, si estuviese en juego. Permaneced delante de Dios hasta que se enciendan en

$43 \quad$ Ibíd., 46.

44 Ellen G. White, "Visits to Philadelphia, New York, and Newark”, Review and Herald, 25 de noviembre, 1909.

45 Ellen G. White, Testimonios para la iglesia (Doral, FL: Asociación Publicadora Interamericana, 1998), 9:187.

46 White, Testimonios para la iglesia, 1:152.

https://doi.org/10.17162/recm.v19i1.1546 
vuestros corazones anhelos indecibles de salvación, y obtengáis la dulce evidencia de que vuestro pecado está perdonado" ${ }^{.47}$

Del mismo modo, al abordar el tema da fe, ella advierte que "es la iglesia de Dios la que ha perdido su fe para pedir, su energía para luchar" . ${ }^{48}$ Así como Jacob, el pueblo de Dios debe clamar: "'No te dejaré, si no me bendices'. Génesis 32:26. La fe perseverante se ha ido muriendo. Debe revivir en el corazón de los hijos de Dios. Se debe solicitar la bendición de Dios. La fe, la fe viva nos eleva siempre hacia Dios y la gloria". ${ }^{49}$

\section{Fuerte clamor: "Salid de ella pueblo mío"}

El apóstol Juan advirtió en Apocalipsis 18:4 que el pueblo remanente debe salir de la Babilonia mística. Este mensaje, que es parte del mensaje de los tres ángeles de Apocalipsis 14, anuncia que se debe abandonar todo aquello que obstaculiza la completa relación con Dios. En ese sentido, Ellen G. White advierte que el pueblo adventista necesita una purificación. Ella señala este propósito al preguntar: “ ¿Reflejas la hermosa imagen de Jesús como deberías?", ella responde: "Prepárate, prepárate, prepárate. Tendrás que morir en el mundo con una muerte mayor como nunca." 50 Por lo tanto, la preparación exige una purificación elevada. A continuación, se presenta una lista de consejos prácticos para la vida del creyente.

\subsection{El "yo" debe ser vencido}

Ellen G. White advierte que: “Debemos negarnos a nosotros mismos a lo largo del camino, morir a nosotros mismos diariamente, y hacer que solo Jesús aparezca, y tener su gloria continuamente a la vista" . ${ }^{51}$ En tal sentido, la manera que Dios tiene para lograr esta purificación es "a través del sufrimiento", para que en el "tiempo de angustia" puedan ver al "Rey en su belleza". ${ }^{2}$ De esta manera, la abnegación se convierte en un elemento fundamental que el creyente debe procurar y así estar en el proeso de preparación para los tiempos dificiles que se avecinan.

$47 \quad$ Ibíd.

48

White, Testimonios para la iglesia, 1:136.

49 Ibíd.

50

White, Christian Experience and Views of Ellen G. White, 52.

$51 \quad$ Ibíd., 54

52 Ibíd. 


\subsection{Preparación de los ministros y sus \\ esposas}

La preparación que deben tener los ministros comienza venciendo el desánimo. Muchos de ellos experimentan este sentimiento "tan fácilmente", que no se dan cuenta de lo que pasaría con ellos "si Dios apartase de ellos su mano". ${ }^{53}$ Segundo, "Los siervos de Dios deben sentir responsabilidad por las almas." ${ }^{54}$ Esta responsabilidad implica trabajar en favor de su salvación hasta exclamar las palabras del profeta: "Perdona, oh Jehová, a tu pueblo" (Jl 2:17). Pero, el trabajo ha sido para algunos muy fácil, ellos "han tenido tan pocas privaciones, y conocen tan poco la necesidad, las fatigas de la labor o las cargas del alma". ${ }^{55}$ Dios ha señalado para ellos,

es necesario que haya un castigo entre los predicadores a fin de eliminar a los perezosos, lerdos y egoístas, para que quede una compañía pura, fiel y abnegada, que no busque su bienestar personal, sino que ministre fielmente en palabra y doctrina, con voluntad de soportarlo todo por causa de Cristo y salvar a los que él redimió con su muerte. Sientan sobre sí estos siervos el ¡ay! que se les aplicará si no predican el Evangelio, y esto bastará; pero no todos lo sienten. ${ }^{56}$

Por estas razones, debe haber una mejor evaluación acerca de la calificación del ministro, porque, "El Señor no confiará la responsabilidad de cuidar su grey a personas que no posean las calificaciones necesarias", sino a "personas de profunda experiencia, probados, de juicio sólido, personas que se atrevan a reprochar el pecado con espíritu de humildad, y que entiendan cómo alimentar a la grey" ${ }^{\prime{ }^{57}}$ En ese sentido, y como promesa divina, se declara que si el ministro es fiel al deber divino de "fomentar la causa, Dios puede confiarnos la herencia eterna"..$^{58}$

También se declara acerca de las esposas de los ministros algunas instruciones. Pablo dejó una serie de consejos en 1 Timoteo 2:9, 10. En ese mismo contexto, Ellen G. White dice sobre las esposas de los ministros del evangelio que profesan la verdad presente, ellas deberían,

\footnotetext{
53 White, Testimonios para la iglesia, 1:124.

$54 \quad$ Ibíd.

55 Ibíd.

56 Ibíd.

$57 \quad$ Ibíd., 1:192.

$58 \quad$ Ibíd., 1:182.
} 
ayudar a sus esposos en sus labores, y cuidar muchísimo la influencia que ejercen; porque hay quienes les observan y esperan más de ellas que de otros. Su indumentaria, su vida y conversación debieran ser un ejemplo que tenga sabor de vida y no de muerte. Vi que deben asumir una actitud humilde y mansa, aunque digna, sin dedicar su conversación a cosas que no tienden a dirigir la mente hacia el cielo. Su gran pregunta debe ser: “¿Cómo puedo salvar mi propia alma, y ser el medio de salvar a otros?" Vi que Dios no acepta una obra tibia al respecto. Quiere todo el corazón y el interés, o nada. Su influencia se ejerce decidida e inequívocamente en favor de la verdad o contra ella. ${ }^{59}$

Ella también advierte que Satanás las está tentando con el orgullo y egoísmo al punto que "se quejan o lamentan abiertamente", "piensan que deben cumplir sus deseos y hacer su voluntad", y de esta manera, "olvidan los sufrimientos de Jesús, su Maestro". ${ }^{60}$ "Estos predicadores permiten que sus compañeras los afecten, los arrastren hacia abajo y llenen su mente de prejuicio" ${ }^{61}$ Por lo tanto, se debe reflexionar en el pecado de Acán (Jos 7) ya que "una esposa no santificada es la mayor maldición que pueda tener un ministro". ${ }^{62}$

\subsection{Advertencias y amonestaciones}

Para muchos es casi imposible realizar una purificación total debido a que "tienen tanta escoria acumulada ante la puerta del corazón que no pueden abrirla"; tienen dificultades entre sus hermanos, "el mal genio o la codicia", y el "robo" ${ }^{63}$ Frente a esta realidad, Dios exhorta que se debe quitar todo tipo de escoria para que el creyente pueda "abrir la puerta y dar la bienvenida al Salvador". ${ }^{64}$

A esto se suma el hecho de que Dios pedirá cuentas de los tesoros terrenales concedidos a sus hijos que debieron ser usados para el avance de Su obra. ${ }^{65}$ Ella advierte a los creyentes que si no son fieles en esto, ellos pueden "fallan en todo" ${ }^{66}$ Asimismo, Ellen G. White menciona que Dios no

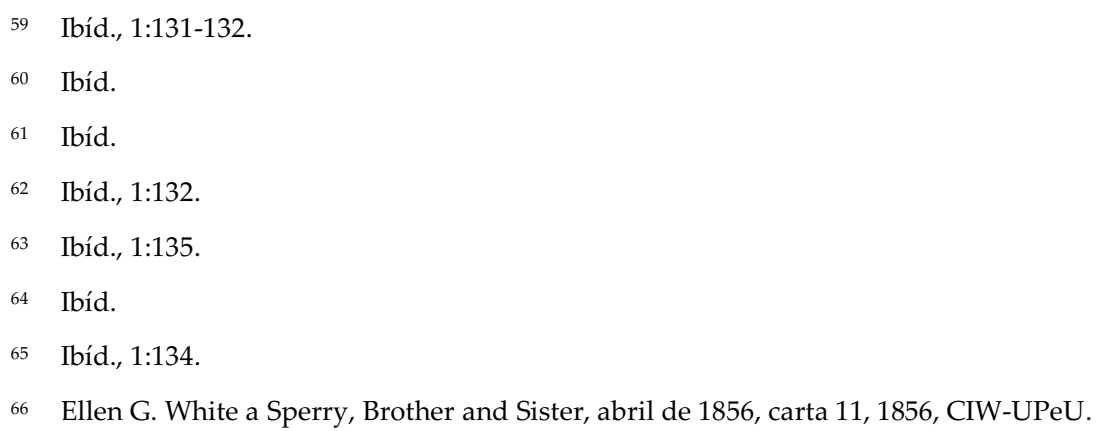


considera "ligeramente los pecados" ${ }^{67}$ Siguiendo esta línea de pensamiento, entre los terribles pecados que traerían maldición a la causa de Dios en los últimos días se encuentran: (1) la violación deliberada del "séptimo mandamiento", ${ }^{68}$ (2) la vestimenta sensual, (3) murmuración contra Dios ${ }^{69},(4)$ casamiento "para cometer lujurias depravadas", ${ }^{70}$ y (5) "artículos innecesarios para decorar el cuerpo". ${ }^{71}$ Frente a todas estas advertencias, Ellen G. White les recuerda el principio de 1 Corintios 10:31.72

También existe una actitud peligrosa para la causa de Dios de parte de los predicadores. La solemnidad del "mensaje del tercer ángel", no debe ser presentado por quienes hacen "bromas y ... chistes" y además se ocupan en "frivolidades", ellos traerán un mal que afectará "a todas nuestras filas". ${ }^{73}$ Esta forma de actuar responde muchas veces a que "se piensa más en la aprobación de los hombres" que en honrar el mensaje de Dios. ${ }^{74}$ Por lo cual ella aconseja poner "en orden vuestro corazón, no sea que él os visite con juicio y sea cortado el débil hilo de la vida, y permanezcáis en el sepulcro sin protección, sin preparación para el juicio"..$^{75}$ También ella advierte sobre lo siguiente: "la casa de Dios es profanada y los hijos de los creyentes del sábado violan el sábado. Corren por la casa [iglesia], juegan, hablan y manifiestan su mal humor en las mismas reuniones donde los santos se han reunido para glorificar a Dios y adorarlo en la belleza de la santidad" . ${ }^{76}$ Además, las personas que abrigan el espíritu de crítica que solo buscan encontrar fallas a los demás, no tendrán lugar en el cielo. ${ }^{77}$ Por tanto, el pueblo de Dios debe purificar su corazón así como purifica su cuerpo, la

68 Ibíd. También se declara que quien conscientemente transgrede el sábado, debiera ser "suspendido de la iglesia". Ibíd.

69 White, Testimonios para la iglesia, 1:122-124.

70 White, MS 3, 1854, CIW-UPeU.

71 White, Testimonios para la iglesia, 1:129.

72 Ibíd., 1:125-127.

73 Ibíd., 1:127.

74 Ibíd.

75 Ibíd.

76 White, MS 3, 1854, CIW-UPeU.

77 White, Testimonios para la iglesia, 1:137. 
ropa, la mente ${ }^{78}$ y las casas, se deben mantener ordenadas y libres de toda impureza. ${ }^{79}$

\subsection{Alimentación}

Ellen G. White también advierte sobre la importancia de la alimentación ya que algunos han hecho "un dios de sus vientres"..$^{80}$ Por eso, ella afirma que "hay alimentos por los cuales no se puede pedir la "bendición de Dios". ${ }^{81}$ Desde esa perspectiva, ella aconseja que es mejor una alimentación sencilla y buena nutricionalmente (Proverbios 30:8), ${ }^{82}$ que fortalezca y desarrolle su fuerza ya que estarán obligados a "ejercer toda la fuerza que tengan" ${ }^{83}$ Ella recuerda que en el tiempo de angustia los "sufrimientos serán mentales, y Dios les proveerá alimentos," 84 a saber, "pan y agua". 85

\subsection{Educación y preparación de los niños}

A través de sus escritos, Ellen $G$. White amonesta que una de las señales de los últimos días es la desobediencia de los niños a sus padres (cf. 2 Ti 3:2). En ese contexto, ella pregunta "ise dan cuenta los padres de su responsabilidad?". ${ }^{86}$ Los padres deben seguir las indicaciones de Jesús quien dijo: “dejad que los niños venir a mi y no se los impidáis" (Mt 19:14). Estas palabras implican educación y corrección, ella señala que "primero deben cumplir con su deber con sus hijos: corregir su temperamento, su desobediencia y sus errores, y luego orar con ellos y para que Dios haga su parte y cambie el corazón y bendiga a los niños" ${ }^{87}$

Considerando el deber de los padres, se debe tener en cuenta que "los padres están en el lugar de Dios para sus hijos y tendrán que rendir

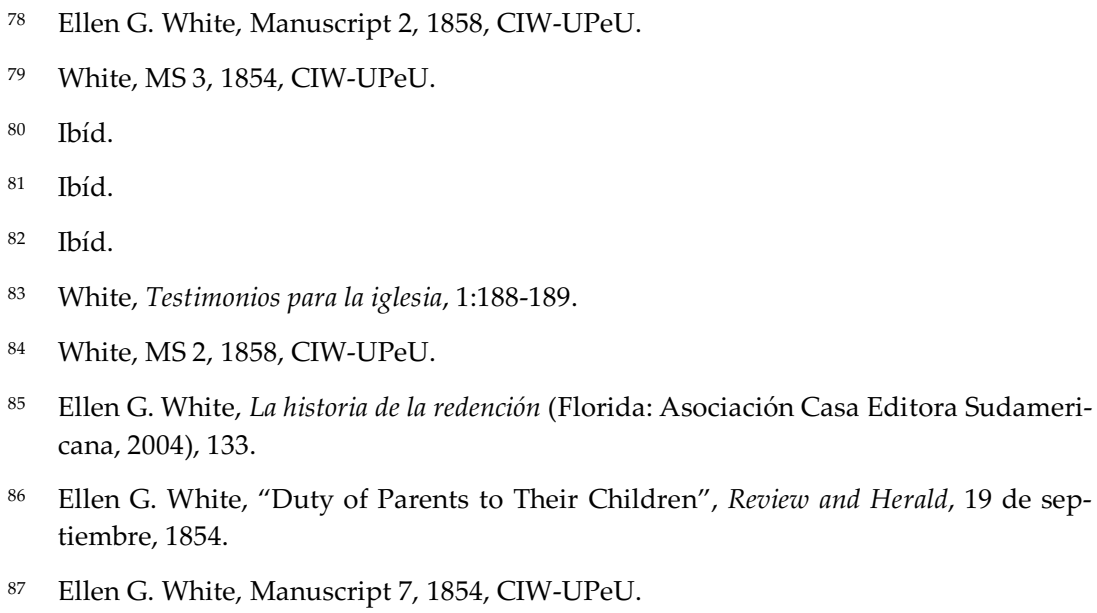


cuentas" ${ }^{88}$ De lo contrario, ella advierte que si no son conscientes de dicha responsabilidad, los padres estarían "criando niños para ser destruidos por el ángel destructor... hijos que podrían haber sido salvados si hubieran actuado como padres fieles" ${ }^{89}$ Por tanto, es deber de los padres de ayudar "a los niños a prepararse", ${ }^{90}$ y no ser encontrado falto en la balanza. ${ }^{91}$

\subsection{Evitar las preocupaciones}

A través de sus escritos, Ellen G. White habla acerca de las preocupaciones. Ella sostiene que "el Señor me ha mostrado el peligro en que estamos de dejar que nuestra mente se llene de pensamientos y congojas mundanales. Vi que algunos ánimos son alejados de la verdad presente y del amor a la Santa Biblia porque leen libros excitantes". ${ }^{92}$ Del mismo modo, habla acerca de los que se preocupan por lo "que han de comer, beber y vestir. Algunos sitúan demasiado lejos en su expectación la venida del Señor". ${ }^{93}$ Tales declaraciones son importantes ya que esta clase de preocupaciones son un "gran peligro", "porque si la mente está embargada por otros asuntos, la verdad presente queda excluida, y no hay en nuestra frente lugar para el sello del Dios vivo". ${ }^{94}$ Ella agrega que,

dejemos que los mandamientos de Dios y el testimonio de Jesús estén siempre presentes en nuestros pensamientos y que ahuyenten las preocupaciones mundanales. Sean ellos nuestra meditación cuando nos acostamos y cuando nos levantamos. Vivamos y actuemos teniendo plenamente en cuenta la venida del Hijo del hombre. El tiempo del sellamiento es muy corto, y pronto terminará. Ahora, mientras los cuatro ángeles están reteniendo los cuatro vientos..$^{95}$

Asimismo, ella menciona que no se sabe cuanto tiempo durará el tiempo de angustia, pero que cada siervo de Cristo "puede saber si sus vidas están escondidas con Cristo en Dios". ${ }^{96}$ 


\subsection{Falsas reformas}

Ellen G. White también advirtió sobre las falsas reformas al afirmar que "Satanás también trabajaría, y que los misteriosos golpes y las señales y maravillas de Satanás y las falsas reformas aumentarían y se extenderían" ${ }^{97}$ El problema con este tipo de manifestaciones "no eran reformas del error a la verdad" sino que con un "atuendo religioso cubría la iniquidad de un corazón vil. Algunos parecían haberse convertido realmente para engañar al pueblo de Dios. Pero si pudieran ver sus corazones, aparecerían tan negros como siempre" ${ }^{\prime 9}$

\section{La iglesia en el tiempo de angustia y su liberación final}

A continuación, se repasará de manera breve los acontecimientos finales que el pueblo de Dios tiene que enfrentar hasta su redención final. Lo primero que debemos tener en cuenta es que antes que se cierre el tiempo de gracia se debe cumplir la profecía hecha por Jesús acerca de la predicación del evangelio a todo el mundo (Mt 24:14). En tal sentido, es necesario que las palabras de Jesús, "yo rogaré al Padre, y os dará otro Consolador, para que esté con vosotros para siempre" (Jn 14:16; cf. 16:7), se hagan realidad y así hacer posible la predicación de la verdad presente. Esta promesa de Cristo implica la presencia plena y permanente del Espíritu Santo. Esta promesa divina ya se cumplió con los discípulos en el día del Pentecostés (Hch 1:4, 2: 1-13; cf. Lc 24:49) y se volverá a cumplir otra vez (Joel 2:28-32). En ese primer Pentecostes, los creyentes fueron investidos plenamente por el poder del Espíritu Santo, el resultado fue que miles entregaron sus vidas a Cristo (p. ej.: Hch 2:14-41, 4:1-4). Así, la manifestación divina es una promesa para los hijos de Dios en el tiempo del fin.

Ahora bien, de la misma manera que sucedió con los discípulos del primer siglo, esta promesa está reservada para el tiempo del fin. Por tanto, el pueblo de Dios debe clamar por la lluvia tardía, tal como declara el profeta Zacarías: “Pedid a Jehová lluvia en la estación tardía. Jehová hará relámpagos, y os dará lluvia abundante y hierba verde en el campo a cada uno" (Zac. 10:1). En este contexto, Ellen G. White señala que, "El mensaje no será llevado adelante tanto con argumentos como por medio de la convicción profunda inspirada por el Espíritu de Dios. Los argumentos ya

97 White, MS 1, 1849, CIW-UPeU.

98 Ibíd. 
fueron presentados". ${ }^{99}$ Asimismo, las publicaciones repartidas serán como "rayos de luz" que "penetrarán por todas partes, la verdad aparecerá en toda su claridad, y los sinceros hijos de Dios romperán las ligaduras que los tenían sujetos" ${ }^{100}$ Como resultado de esta obra, muchos se unirán al pueblo de Dios.

No obstante, antes del fin del tiempo de gracia comenzará el tiempo de angustia previo por causa del anuncio de la verdad. Ellen $\mathrm{G}$. White explica:

Vi que Dios tenía hijos que no reconocen ni guardan el sábado. No han rechazado la luz referente a él. Y al empezar el tiempo de angustia, fuimos henchidos del Espíritu Santo, cuando salimos a proclamar más plenamente el sábado. Esto enfureció las otras iglesias y a los adventistas nominales, pues no podían refutar la verdad sabática, y entonces todos los escogidos de Dios, comprendiendo claramente que poseíamos la verdad, salieron y sufrieron la persecución con nosotros. Vi guerra, hambre, pestilencia y grandísima confusión en la [T]ierra. Los impíos pensaron que nosotros habíamos acarreado el castigo sobre ellos, y se reunieron en consejo para raernos de la tierra, creyendo que así cesarían los males. ${ }^{101}$

Ella aclara también que el tiempo de angustia no inicia cuando sean "derramadas las plagas; sino a un corto período precisamente antes que caigan, mientras Cristo está en el santuario. En ese tiempo, cuando se esté terminando la obra de la salvación, vendrá aflicción sobre la [T]ierra, y las naciones se airarán, aunque serán mantenidas en jaque para que no impidan la realización de la obra del tercer ángel" ${ }^{102} \mathrm{Al}$ comenzar esta crisis la fe de muchos será puesta a prueba y mientras los "cuatro ángeles de pie sobre los cuatro ángulos de la tierra", detienen "los cuatro vientos de la tierra" todavía hay esperanza de salvación (cf. Ap 7:1-3).

\subsection{Ley dominical sin decreto de muerte}

En Apocalipsis 13:11-14 se encuentra la explicación profética del por qué las persecuciones toman su lugar en el tiempo del fin. Esto sucede a causa de la adoración impuesta por la segunda bestia -Estados Unidos-, a toda la humanidad. El texto advierte que se le ha permitido hacer "grandes señales, de tal manera que incluso hará descender fuego del cielo a la tierra

99 Ellen G. White, El conflicto de los siglos (Doral, FL: Asociación Publicadora Interamericana, 2007), 597.

100 Ibíd.

101 White, Primeros escritos, 33.

102 Ibíd., 85. 
delante de los hombres" (v. 13), obra que será realizada por medio del espiritismo. Debemos notar que el mundo será engañado con tales señales y obligará "a los habitantes de la tierra que le hagan una imagen a la bestia [papado] que fue herida de espada y revivió" (v. 14).

Asimismo, Ellen G. White describe que: "Cuando los Estados Unidos, el país de la libertad religiosa, se una con el papado para forzar la conciencia y obligar a los hombres a honrar el falso día de reposo, los habitantes de todo país del globo serán inducidos a seguir su ejemplo". ${ }^{103}$ Estos decretos dominicales al inicio no serán exclusivamente por causa religiosa sino por causa de que los gobernantes mantengan y ganen popularidad, tal como ella explica,

Por calumnias y airados llamamientos, despertarán las pasiones del pueblo. No teniendo un "así dicen las Escrituras" para presentarlo contra los defensores del sábado bíblico, recurrirán a promulgaciones opresivas para suplir la falta. Para obtener popularidad y apoyo, los legisladores cederán a la demanda de una ley dominical. Los que temen a Dios no pueden aceptar una institución que viola los preceptos del Decálogo. Sobre este campo de batalla se produce el último gran conflicto de la controversia entre la verdad y el error. Y no se nos deja en duda en cuanto al resultado. Ahora, como en los días de Mardoqueo, el Señor vindicará su verdad y su pueblo. ${ }^{104}$

Tanto el mundo como los hijos de Dios estarán sufriendo diferentes tipos de luchas y problemas que no podrán ser controlados e irán creciendo en intensidad. Además, ella explica que la historia del pasado se repetirá:

Se repetirá la historia. Será ensalzada la falsa religión. El primer día de la semana, un día común de trabajo que no tiene ninguna santidad, será erigido como la imagen de Babilonia. Se ordenará a todas las naciones y lenguas y pueblos que rindan culto al falso día de reposo [...]. El decreto que ordena el culto de este día [el domingo] será promulgado en todo el mundo. ${ }^{105}$

Esto será como en los días del profeta Daniel, Nabucodonosor obligó a adorar la estatua hecha de oro que lo reconocía como el único rey del mundo antiguo. Este decreto se hizo posible por medio de la unión del poder civil y religioso (cf. Dn 3:1-6). Del mismo modo, estas leyes dominicales esconden su propósito final que es adorar a la primera bestia -el papado-, y su imagen - Estados Unidos- (cf. Ap 13).

103 Ellen G. White, Eventos de los últimos días (Doral, FL: Asociación Publicadora Interamericana, 2009), 116.

104 Ellen G. White, Consejos para la iglesia (Doral, FL: Asociación Publicadora Interamericana, 1991), 610.

105 White, Eventos de los últimos días, 116. 


\subsection{Abandono de las grandes ciudades - Inicio de la persecución}

Ellen G. White menciona que la señal para huir de las grandes ciudades será el decreto que imponga el día de descanso dominical. Ella señala:

Así como el sitio de Jerusalén por los ejércitos romanos fue la señal para que huyesen los cristianos de Judea, así la asunción de poder por parte de nuestra nación [los Estados Unidos], con el decreto que imponga el día de descanso papal, será para nosotros una amonestación. Entonces será tiempo de abandonar las grandes ciudades. ${ }^{106}$

La predicción dada por Jesús se cumplirá "cuando veáis en el Lugar santo la abominación desoladora de la que habló el profeta Daniel -el que lee, entienda-, entonces los que estén en Judea, huyan a los montes" (Mt 24:15-16).

\subsection{Ley dominical con decreto de muerte}

Las leyes dominicales impuestas llegarán a su clímax cuando la libertad de conciencia y adoración se limite a un falso día de reposo, el domingo. De esta manera, los poderes de este mundo intentarán reemplazar el sábado bíblico y declarar en su lugar el domingo como el día santo. Entonces la imagen de la bestia - Estados Unidos-, obligará a adorar a la bestia - el papado-. En ese contexto, aquellos que se negaren a seguir dicho decreto sean "pequeños y grandes, ricos y pobres, libres y esclavos" serán condenados a muerte. Además, se les impondrá una marca en sus frentes o en sus manos para que "ninguno pudiera comprar ni vender, sino el que tuviera la marca o el nombre de la bestia o el número de su nombre" (Ap $13: 15-17){ }^{107}$

\subsection{Abandono de las pequeñas ciudades}

En este contexto de la ley dominical y un decreto de muerte incluído, las palabras de Jesús se cumplirán:

El que esté en la azotea, no descienda para tomar algo de su casa; y el que esté en el campo, no vuelva atrás para tomar su capa. Pero ¡ay de las que estén encinta y de las que críen en aquellos días! Orad, pues, que vuestra huida no sea en invierno ni en sábado, porque habrá entonces ricana,1998), 5:439.

107 Ellen G. White registra de la misma manera este evento. Ellen G. White, Testimonios para la iglesia (Doral, FL: Asociación Publicadora Interamericana, 1998), 8:128. 
gran tribulación, cual no la ha habido desde el principio del mundo hasta ahora, ni la habrá (Mt 24:17-21).

Cuando el decreto de muerte sea impuesto, el pueblo de Dios debe entender que esta será la señal para huir de las pequeñas ciudades. Ellen G. White advierte:

Cuando el decreto promulgado por los diversos príncipes y dignatarios de la cristiandad contra los que observan los mandamientos, suspenda la protección y las garantías del gobierno y los abandone a los que tratan de aniquilarlos, el pueblo de Dios huirá de las ciudades y de los pueblos y se unirá en grupos para vivir en los lugares más desiertos y solitarios. Muchos encontrarán refugio en puntos de difícil acceso en las montañas. ${ }^{108}$

En esas circunstancias, la fe será puesta a prueba y muchos apostatarán debido a su incredulidad sobre la forma en que Dios los va a librar de la prueba final. En ese tiempo los hijos fieles de Dios serán sellados,

Un ángel que regresa de la tierra anuncia que su obra está terminada; el mundo ha sido sometido a la prueba final, y todos los que han resultado fieles a los preceptos divinos han recibido "el sello del Dios vivo".

Entonces Jesús dejará de interceder en el santuario celestial. Levantará sus manos y con gran voz dirá "Hecho es". 109

En ese momento, mientras el mundo viva en aparente paz, se cumplirán las palabras del apóstol Pablo que declara que cuando se proclame "'Paz y seguridad', entonces vendrá sobre ellos destrucción repentina, como los dolores a la mujer encinta, y no escaparán" (1 Tes 5:3).

\subsection{Persecución después del cierre del tiempo de gracia}

El libro de Apocalipsis, describe el cierre del tiempo de gracia cuando se declara: "El que es injusto, sea injusto todavía; el que es impuro, sea impuro todavía; el que es justo, practique la justicia todavía, y el que es santo, santifíquese más todavía" (Ap 22:11). Luego de esto, se desatará un gran tiempo de angustia sin precedentes (Dn 12:1), pero el pueblo de Dios será guiado y protegido por el agente divino. Es en este momento que los ángeles que están "deteniendo los cuatro vientos de la tierra", dejarán de cumplir su labor protectora (Ap 7:1). Esto implica que las plagas postreras serán derramadas sobre la tierra sobre los impíos, pero los hijos de Dios no sufrirán de estas plagas (Ap 16).

108 White, El conflicto de los siglos, 610.

109 Ibíd., 599. 
Cuando la persecución esté llegando a su clímax, Dios cuidará a su pueblo en los lugares desolados, y aunque algunos serán encarcelados y otras serán abandonados, Dios no los abandonará. Ellen G. White agrega,

Como los cristianos de los valles del Piamonte, convertirán los lugares elevados de la tierra en santuarios suyos y darán gracias a Dios por las "fortalezas de rocas". Isaías 33:16. Pero muchos seres humanos de todas las naciones y de todas clases, grandes y pequeños ricos y pobres, negros y blancos, serán arrojados en la más injusta y cruel servidumbre. Los amados de Dios pasarán días penosos, encadenados, encerrados en cárceles, sentenciados a muerte, algunos abandonados adrede para morir de hambre y sed en sombríos y repugnantes calabozos. Ningún oído humano escuchará sus lamentos; ninguna mano humana se aprontará a socorrerlos. ${ }^{110}$

\subsection{Tiempo de angustia de Jacob - Fin de la persecución}

Mientras los impíos sufren las plagas postreras, el pueblo de Dios será cuidado, protegido y alimentado por Dios. Sin embargo, los fieles experimentarán una angustia mental por causa del perdón de sus pecados. Jeremías dice que ese día no tendrá comparación, pues será "un tiempo de angustia para Jacob", pero Dios promete librarlos (Jer 30:7). Esta profecía responde a la experiencia de Jacob cuando temió por su vida pues su condición moral le hacía pensar que no había sido perdonado y porque Esaú su hermano lo buscaba para matarlo (Gn 32:24-30).

De la misma manera, en el tiempo del fin, los hijos de Dios temerán por su vida por las mismas razones. Sin embargo, "si Jacob no se hubiese arrepentido previamente del pecado que cometió... Dios no habría escuchado su oración ni le hubiese salvado".111 Por lo tanto, así com Dios liberó a Jacob a causa de su actitud, aquellos hijos de Dios que pasen por el tiempo de angustia requerirán la misma actitud de arrepentimiento de sus pecados para experimentar la gran liberación de Dios. ${ }^{112}$ La fe de los hijos de Dios será severamente probada, "este fue el tiempo de la angustia de Jacob. Entonces todos los santos clamaron en angustia de ánimo y fueron libertados por la voz de Dios. ${ }^{113}$

Por otro lado, quienes no aceptaron el mensaje de la verdad presente contemplarán su destrucción por causa de las plagas postreras. En ese

\footnotetext{
110 Ibíd., 610.

111 Ibíd., 605.

112 Ibíd.

113 White, Primeros escritos, 36.
} 
contexto, los gobernantes pensarán que las plagas son por causa de los que guardan el sábado. De esta manera empezará la persecución final que se extenderá por todo el mundo con una sed de muerte sin precedentes,

Se demandará con insistencia que no se tolere a los pocos que se oponen a una institución de la iglesia y a una ley del estado; pues vale más que esos pocos sufran y no que naciones enteras sean precipitadas a la confusión y anarquía. Este mismo argumento fue presentado contra Cristo hace mil ochocientos años por los "príncipes del pueblo". "Nos conviene-dijo el astuto Caifás - que un hombre muera por el pueblo, y no que toda la nación se pierda". Juan 11:50.... El romanismo en el Viejo Mundo y el protestantismo apóstata en la América del Norte actuarán de la misma manera contra los que honren todos los preceptos divinos. ${ }^{114}$

Del mismo modo, se describe este tiempo como sigue:

Fue una hora de tremenda y espantosa angustia para los santos. Día y noche clamaban a Dios para pedirle que los librase. A juzgar por las apariencias no había posibilidad de escapar. Los malvados, saboreando de antemano su triunfo, exclamaban: “¿Por qué no os libra vuestro Dios de nuestras manos? ¿Por qué no os escapáis por los aires para salvar la vida?" Pero los santos no los escuchaban. ${ }^{115}$

Entre la sexta y la séptima plaga el Armagedón ${ }^{116}$ tomará su lugar, trayendo mucha aflicción y angustia. Ellen G. White advierte que durante "las últimas escenas de la historia de la tierra, se desencadenará la guerra. Habrá pestilencias, plagas y hambre. Las aguas de las profundidades desbordarán sus límites. La propiedad y la vida serán destruidas por el fuego y la sangre". ${ }^{117}$ En ese contexto, los esclavos serán liberados y los que sufrieron en las cárceles serán liberados de una manera sobrenatural y al final se escuchará un "potente grito por la victoria lograda sobre la bestia y su imagen". ${ }^{118}$

\footnotetext{
114 White, El conflicto de los siglos, 601.

115 White, Primeros escritos, 283.

116 Jacques B. Doukham menciona que el nombre Armagedón "expresa el destino que les espera a los idólatras de Babel: un día de llanto como ningún otro." Jacques B. Doukham, Secretos del Apocalipsis (Florida: Asociación Casa Editora Sudamericana, 2007), 170 .

117 Ellen G. White, "Words of Comfort", Review and Herald, 19 de octubre, 1897.

118 White, Primeros escritos, 34-35.
}

https://doi.org/10.17162/recm.v19i1.1546 


\subsection{La resurrección especial}

Entonces, luego de los momentos mas difíciles que le toque vivir al pueblo de Dios en el tiempo del fin, habrá una resurrección especial. Las palabras del profeta Daniel (12:2) se cumplirán. Ellen G. White agrega:

Todos los que murieron en la fe del mensaje del tercer ángel, salen glorificados de la tumba, para oír el pacto de paz que Dios hace con los que guardaron su ley. "Los que le traspasaron" (Apocalipsis 1:7), los que se mofaron y se rieron de la agonía de Cristo y los enemigos más acérrimos de su verdad y de su pueblo, son resucitados para mirarle en su gloria y para ver el honor con que serán recompensados los fieles y obedientes. ${ }^{119}$

De pronto, se escuchará la voz de Dios que anuncia la hora de su venida, pero para los impíos será como una conmoción de la naturaleza,

Pero había un espacio de gloria fija, del que, cual estruendo de muchas aguas, salía la voz de Dios que estremecía cielos y tierra. El firmamento se abría y cerraba en honda conmoción. Las montañas temblaban como cañas agitadas por el viento y lanzaban peñascos en su derredor. El mar hervía como una olla y despedía piedras sobre la tierra. $\mathrm{Y}$ al anunciar Dios el día y la hora de la venida de Jesús, cuando dio el sempiterno pacto a su pueblo, pronunciaba una frase y se detenía de hablar mientras las palabras de la frase rodaban por toda la tierra. ${ }^{120}$

\subsection{Segunda venida}

Finalmente, y luego de los eventos referidos, se cumplirá lo que Juan dijo: "He aquí que viene con las nubes: Todo ojo lo verá, y los que lo traspasaron; y todos los linajes de la tierra se lamentarán por causa de Él. Sí, amén" (Ap 1:7). Entonces, las palabras de Jesús, "veréis al Hijo del hombre sentado a la diestra del poder de Dios y viniendo en las nubes del cielo" (Mt 26:64), llegarán a ser realidad para el pueblo de Dios de todas las edades.

\section{Conclusión}

Pastorear al pueblo de Dios es desafiante. Cuanto más será en tiempos de crisis cuando la gran apostasía tenga su lugar. A través de sus escritos Ellen G. White menciona que la preparación previa a estos eventos será significativa para salir victoriosos. Así, tanto ministros como miembros de iglesia tienen que ser purificados por medio de la aceptación del mensaje

119 White, El conflicto de los siglos, 621.

120 White, Primeros escritos, 34.

https://doi.org/10.17162/recm.v19i1.1546 
de los tres ángeles de Apocalipsis 14 y ser llenos del Espíritu Santo. Así, siendo revestidos por el poder de Dios, se podrá dar el último mensaje de amonestación al mundo y recibir el sello de Dios debido a la obediencia a Dios y a su Palabra. Asimismo, el sábado será la señal visible del pacto entre Dios y los suyos. Este sello será la cobertura que los hijos de Dios recibirán cuando sean derramadas las plagas postreras y serán cuidados durante los momentos más difíciles que se verán en la faz de la Tierra, hasta que se haga realidad su redención final cuando Cristo los lleve consigo mismo en su segunda venida. 